\title{
"Mysterium" y "sacramentum" hasta San Agustín
}

La doctrina agustiniana sobre los sacramentos tiene en la tradición precedente de la Iglesia una fuente reconocida y el Santo no se ha separado de ella, sino que ha profundizado algunos de sus aspectos y ha enmarcado su pensamiento en el cuadro de sus enseñanzas generales. Como tendremos ocasión de ver con más detenimiento, en la secuencia de sus concepciones humanas se engrana toda la realidad como sacramento o signo sensible de una presencia divina, que tendrá una expresión más idefinida en los hoy llamados técnicamente sacramentos, pero que, en su sentir, eran dos principales, o mejor dicho tres, bautismo, eucaristía y ordenación sagrada. Sin embargo no podemos entrar directamente en su manera de concebir la sacramentaria, sino que preferimos limitarnos aquí a los precedentes.

La Escritura y la tradición, sobre todo litúrgica, han sido los dos puntos clave de la evolución de la doctrina sacramental. El Concilio de Trento tiene conciencia de este hecho y así en el Proemio del Decreto sobre los Sacramentos, en la Sesión VII -3 de marzo de 1547- decía :

\footnotetext{
"Propterea sacrosancta oecumenica et generalis Tridentina Synodus... ad errores eliminandos, et exstirpandas haereses, quae circa ipsa sanctissima sacramenta hac nostra tempestate, tum de damnatis olim a Patribus nostris haeresibus suscitatae, tum etiam de novo adinventae sunt, quae catholicae Ecclesiae puritati et animarum saluti magnopere officiunt: sanctarum Scripturarum doctrinae, apostolicis traditionibus atque aliorum Conciliorum et Patrum consensui inhaerendo, hos praesentes canones statuendos et decernendos censuit, reliquos, qui supersunt ad coepti operis perfectionem, deinceps (divino Spiritu adiuvante) editura" 1.
}

El otro Concilio que entraba en juego en este Decreto y al que principalmente se alude, como se hará luego en los sacramentos particulares, es el Concilio de Florencia, que en la Bula de Unión de los

1 DS 1600. 
Armenos "Exsultate Deo" del 22 de noviembre de 1439, da una instrucción sobre los sacramentos, tomada en gran parte del opúsculo de Santo Tomás De articulis fidei et Ecclesiae sacramentis ${ }^{2}$.

La discusión preparatoria de ese Decreto del Tridentino muestra con evidencia que se ha recurrido a los Padres de la Iglesia de modo especial y que cada uno de los ponentes y oponentes busca textos patrísticos para probar sus asertos. El autor que se lleva la palma es San Agustín, que sobresale en la doctrina sacramentaria, quizá más que en ninguna otra. Basta abrir las Actas de esas Congregaciones generales para darse contra esa evidencia. Agustín, a quien, por otra parte, recurrían los reformadores ${ }^{3}$, viene citado también con preferencia en las Congregaciones generales. Su doctrina había guiado el pensamiento de las disquisiciones teológicas de los siglos medios ${ }^{4}$. En sacramentaria el genio de Hipona ha hecho progresar la teología de modo extraordinario. Así lo reconocen los autores y así do prueba la historia. "La controversia con los donatistas —escribe Tixeront- no versaba solamente sobre la noción de Iglesia, versaba más bien sobre las condiciones de validez de los sacramentos. Ella ha dado, pues, a San Agustín la ocasión para explicarse y emitir sobre el particular una serie de visiones que han ofrecido en la teología ide los sacramentos un progreso decisivo" "5. Por su parte Morel nos asegura con mayor claridad: "San Agustín ha legado a la teología occidental las grandes líneas de su doctrina sacramentaria. Todas las Iglesias de Occidente se reclaman más o menos a él a pesar de sus oposiciones doctrinales. Puede decirse que lo que las diversas doctrinas sacramentarias tienen de común es de origen agustiniano. Pero se puede decir que cuanto tienen de contradictorio es también de origen agustiniano. La admirable síntesis del Doctor de Africa ha dejado un cierto número de dificultades sin respuesta. $\mathrm{Y}$ en resolver

2 DS 1309-1310.

3 Calvino había escrito: "Contentus ero paucis ostendere sine controversia totum (Augustinum) esse nostrum" (Inst. relig. christ. IV, 17, 28; Corp. Reform. Opera Calvini, ed. Baum, Cunitz, Reuss, II, 1927, citado por Villette, p. 217); cf. J. Bechmann, Vom Sakrament bei Calvin. Die Sakramentslehre Calvins in ihrem Beziehungen zu Augustin, Tübingen 1926; J. CAdIOU, "Calvin et saint Augustin": Augustinus Magister. II, Paris 1954, 1039-1056.

4 Citaremos solamente un artículo interesante de G. GEENEN, "Les "auctoritates" dans la doctrine du baptême chez saint Thomas d'Aquin": Ephemerides Theologicae Lovanienses 15 (1938) 279-329.

5 J. TIXERONT, Histoire des dogmes dans l'Antiquité chrétienne. II De saint Athanase à saint Augustin (318-430), 6 edic., Paris 1921, 396. 
esas dificultades se han esforzado los teólogos posteriores" " 6 . Y en un estudio detallado y muy lleno Villette iniciaba de este modo el análisis de San Agustín: "El interés de la doctrina sacramentaria de San Agustín reside en la admirable variedad de matices que contiene. En esta variedad radica también su dificultad: en razón de su riqueza y del hecho que no ha sido nunca sistematizada por su autor, esta doctrina ha podido dar lugar a las interpretaciones más contradictorias. Periódicamente, largas controversias han opuesto a este respecto los mayores nombres de la teología, llegando a veces a desgarrar la Iglesia. Después de la Reforma, cada cual la revindica por suya. Lutero y Calvino pretendían hacer de ella un arma contra los teólogos de la Iglesia; éstos, por su lado, acumularon para responderles los tratados más voluminosos, a veces muy virulentos. En nuestros días aún, los trabajos por lo demás más irénicos, de P. Battifol (1905, 1913), de K. Adam (1908), E. Hocedez (I9I0), J. Lebreton (I9II), G. Lecordier (I930), H. M. Féret (1940), P. Th. Camelot (1947), para citar sólo los más importantes, conservan siempre el deseo de poner en luz el pleno acuerdo de la doctrina agustiniana con la fe católica más estricta" ".

Admitiendo todos estos hechos como datos que la historia de la teología puede probarnos, es preciso dejar constancia de que la doctrina agustiniana sobre los sacramentos, por compleja y profunda, ha sido parcialmente interpretada tanto por los católicos como por los hermanos separados. Cuando la enmarcamos en la enseñanza general de la iglesia precedente al Obispo de Hipona y contemporánea suya, descubrimos que la tradición se prosigue en él con cierta fidelidad y que sus visiones no se alejan, sino que profundizan datos ya adquiridos. Por eso antes de entrar en el estudio de los sacramentos en San Agustín, queremos situarlo en su momento histórico con la carga de tradición que pesa sobre sus concepciones.

\section{I. "Mysterium" y "Sacramentum" en los Padres.}

El Concilio de Trento nos daba opción para estudiar los sacramentos en los Padres, pero a su vez nos crea una dificultad: en él se da

6 B. MoREL, Le signe sacré. Essai sur le sacrement comme signe et information de Dieu, Paris 1959, 23.

7 L. VILLETTE, Foi et Sacrement. Du Nouveau Testament à saint Augustin, Paris 1959, 217. 
por supuesta una definición casi unívoca. Sin embargo hay una anotación digna de tenerse en ouenta. Al examinar los artículos sobre los sacramentos en general, había uno que condenaban los teólogos y que decía: "Sacramenta novae legis non conferre gratiam, etiam non ponentibus obicem" 8 . El Cardenal Seripando apostillaba y llamaba a la reflexión en estos términos:

"Convenio cum theologis propter illam sacramenti definitionem quam ex priscis doctoribus collegit Magister: "Sacramentum est invisibilis gratia, visibilis forma, cujus imaginem gerit et causa existit", cuius definitionis mentio fieri posset in proemio ad vitandam aequivocationem, etc. Multis enim modis hoc nomen sumitur" 9 .

Quizá esta anotación del agustino Seripando hubiera disuelto muchos malentendidos. Aparece en ella una conciencia clara de las múltiples acepciones de la palabra "sacramentum". Se trataba, en sentir de Seripando, de evitar equívocos y para ello pedía una mención de la definición aceptada. Sin embargo explícitamente la definición no se ha dado, aunque pueda colegirse de los diferentes cánones. Se aprecia que la definición recibida es la escolástica y tal vez solamente la de una tendencia. No extraña, pues, nada que la discusión se continuara.

$Y$ he aquí ya la primera cuestión: Esa definición ¿está conforme con la Escritura y con la tradición, o es más bien producto de la especulación medieval? ¿Cómo se ha llegado a una formulación semejante, o a una tal seguridad terminológica? ¿El contenido que se ha dado a la palabra corresponde realmente a cuanto ha captado en ella la Sagrada Escritura y la tradición patrística y litúrgica? El Concilio afirmaba en el Proemio que se adhería a la Escritura, a las tradiciones apostólicas y a la doctrina de los Padres, ¿pero es verdad de hecho? $¿$ No ha sido también unilateral en la apreciación, dejando en la oscuridad, en período polémico, otros aspectos de la doctrina que los Padres han puesto también de relieve? ¿No se ha ido a un cierto automatismo en la producción de la gracia, pasando por alto el aspecto personal de la propia colaboración? Cuanto el Concilio ha dicho es verdad, pero hay otras muchas verdades vividas por los fieles y expresadas en la

8 Concilii Tridentini Actorum Pars altera. Acta post Sessionem Tertiam usque ad Concilium Bononiam translatum collegit edidit illustravit Stephanus EHSES, Friburgi Brig., 1911, V, 863.

$9 \quad$ Ibid. 962. 
Escritura y en la Tradición que el Concilio no ha acentuado y apenas ha insinuado.

La teología sacramentaria hoy vuelve a los Padres de la Iglesia y no puede reducirse a una exposición más o menos racionalizada con la ayuda de las categorías escolásticas. Sería cerrarnos al descubrimiento de la vivencia profunda de la espiritualidad sacramentaria, a la que invitaban sobre todo los Padres y necesita el pueblo cristiano. Los nuevos estudios sobre los sacramentos viajan hoy por esta vía, ya antigua, y sin olvidar ni ir contra lo definido insisten más en el aspecto personalista, espiritual y pastoral, como aspectos más bíblicos y más patrísticos ${ }^{10}$. La bibliografía sobre los términos "musterion" y "sacramentum" en los Padres es abundante ${ }^{11}$ y los lugares en que vienen usados por los escritores eclesiásticos han sido estudiados en diferentes ocasiones. Michel, tras un recorrido por los textos patrísticos, en busca del contenido y de la definición de esos términos, concluye con estas palabras: "De este estudio preliminar de la palabra "sacramento" aplicado a los ritos misteriosos empleados por la Iglesia en la iniciación y la vida religiosa de sus miembros, se idesprende ya un doble concepto: la idea de signo y la idea de santificación. Un signo sagrado porque simboliza una realidad santa, un signo eficaz, porque produce él mismo la santificación en el alma. "Símbolo eficaz de santificación", he aquí cómo el sacramento cristiano aparecía bajo las fórmulas todavía hesitantes por las que los primeros autores latinos han hecho la trasposición de musterion en sacramentum" ${ }^{12}$. Michel iba en busca del contenido y, a su juicio, lo ha encontrado.

10 Pueden verse los estudios de J. Daniélou, de Th. Camelot, de Schillebeeckx.

11 Recogemos unos cuantos títulos y pueden verse algunos otros en las páginas que siguen: L. BouYER, "Mystérion": Supplément à la Vie Spirituelle 23 (nov. 1952) 397-406; J. DE GHELLINCK - E. de BACKER - J. PouKENS - G. LEBACQZ, Pour l'histoire du mot "sacramentum", Louvain 1924; J. DorgNon, "Sacrum, Sacramentum, Sacrificium dans le texte latin du livre de la Sagesse": Revue des Etudes Latines 32 (1954) 51-52; 43 (1956) 240-253; V. GRöNE, Sacramentum oder Begriff von Sacrament bis zur Schelastik, Brilon 1853; Ch. MoHrmann, "Sacramentum dans les plus anciens textes chrétiens": The Harvard theological Review 47 (1954) 141-152. Publicado también en Études sur le latin des chrétiens. (Storia e Letteratura. Raccolta di Studi e Testi, 65), Roma 1958, 233-244 (aquí citaremos por este volumen); M. R. SAINIo, Semasiologische Untersuchungen über die Entstehung der christlichen Latinität, Helsinski 1940, principalmente p. 75-86; M. VERHEIJEN, "Mysterion, Sacramentum et la Synagogue": Recherches de science religieuse 45 (1957) 321-337; H. vON SODEN, "Mysterion und Sacramentum in der ersten drei Jahrhunderten der Kirche": Zeitschrift für die Neutestrmentliche Wissenschaft 12 (1911) 188-227.

12 A. MICHEL, "Sacrements": Dictionnaire de Théologie Catholique XIV, 1 , cols. $494-495$. 
Sin embargo, a la vista de los textos patrísticos ${ }^{13}$ y de la bibliografía sabre los mismos, se imponen unas primeras conclusiones:

a) Leyendo los textos de los escritores eclesiásticos de los primeros siglos queda uno sorprendido de la multiplicidad de sentidos y significaciones que se dan a la palabra "sacramentum" y aún los mismos griegos a "musterion". Esto nos obliga a un resumen de conclusiones especializadas sobre la evolución semántica de esas palabras.

b) No se puede buscar en los Santos Padres una definición unívoca de "sacramentum", aunque poco a poco se hayan ido agregando algunos elementos a su significación. Ir a buscar la definición de la escuela a los Padres es prejuzgar el sentido de sus propias palabras. Es, en historia de la teología y del dogma, un método muy peligroso y por desgracia muy seguido.

c) La noción de "sacramento" es preciso extraerla de la descripción de los diversos sacramentos, procurando no imponerles categorías que no entraban en la estructura mental de los escritores eclesiásticos ni de la liturgia del tiempo. A veces se piensa que el mero hecho de llamar sacramento al bautismo o a la confirmación da opción a hablar de verdadero y auténtico sacramento, tal como lo entendemos hoy. En cambio en el contexto histórico, doctrinal y filológico era natural que se les llamara de ese modo. Lo único que podría decirse es que la evolución y el desarrollo no se concluye con los Padres y que el progreso se continúa hacia una clarificación de conceptos.

"Musterion" y su Empleo--Se precisaría aquí un estudio completo del uso en singular, pero mucho más en plural en la literatura profana, teniendo en cuenta las discusiones de los filólogos sobre el origen de la palabra y su significado primitivo. Parece adquirido que venga de la raíz mu-, o del sánscrito mus-. En ambos casos tiene la primera significación de "cosa oculta, secreta", aunque no faltan quienes niegan esta procedencia. Sin entrar en la discisión, nos atendremos a

13 Estos textos pueden verse coleccionados en Texte der Kirchenväter. Eine Auswahl nach Themen geordnet. Zusammengestellt und herausgegeben von Alfons HEILmanN unter wissenschaftlicher Mitarbeit von Heinrich KRAFT. Zweiter Band, Kösel-Verlag München 1963, 243-313, sobre los sacramentos en los Padres sin comentario y en traducción alemana; P. F. PALMER, Sacraments and Worship. Liturgy and Doctrinal Development of Baptism, Confirmation and the Eucharist. Edited with commentary by (Sources of christian Theology, 1), 2 edic., London 1957; Sacraments and Forgiveness. (Soumces of Christian Theology, 2), London 1959. Lo mismo puede verse en los demás escritos que citaremos en estas páginas sobre sacramentos o escritores eclesiásticos concretos. 
ios estudiosos del tema, que han puesto, por otra parte, en relación las significaciones de "musterion" en la literatura pagana con el "mysterium" del Nuevo Testamento y en especial de San Pablo ${ }^{14}$.

En breve, podría decirse con Zorell que el significado profano de la palabra es el siguiente: "Para los griegos profanos misterio es una cosa religiosa secreta, conocida solamente por pocos y que no estaba permitido a los iniciados comunicar con los profanos; los misterios eran ciertas doctrinas ocultas y ceremonias sagradas que solían hacerse solemnemente en ciertos días establecidos. De entre ellos las más célebres fueron las Eleusinas" ${ }^{15}$. Tras este sentido profano, doble en singular y en plural, refiere las varias significaciones del término, dadas las cuarenta y cinco veces que es usado en la Escritura, traduciendo unas veces a sốd hebreo y otras a raz, empleado en Dan. 2, 19, 27-29, 47, designando el secreto desconocido e ininteligible del sueño de Nabucodonosor.

En el Antiguo Testamento, en la traducción de los LXX, el término "musterion" significa las siguientes realidades:

a) Misterio, ceremonias de los gentiles.

b) El secreto consejo de Dios.

c) Cualquier secreto.

d) Una realidad oculta al entendimiento humano que no puede ser conocida sino por revelación divina, como la significación del sueño de Daniel.

Y en el Nuevo Testamento se topa con las significaciones probadas en el estudio con los textos correspondientes:

A) Una verdad revelada por Dios, escondida por sí misma al entendimiento humano, una doctrina secreta que se manifiesta por revelación divina, dogmas de fe divinamente revelados. $\mathrm{Y}$ todo ello viene a la luz en diferentes contextos, a saber:

a) En general, como "musteria Theou", aue son verdades comisionadas al magisterio apostólico, y se concretan en los misterios de la fe, en los misterios del Evangelio, los misterios de la piedad, los misterios del reino, siendo todos los genitivos una especie de objetos del misterio.

14 Cf. H. LESETRE, "Mystère": Dictionnaire de la Bible V, cols. 1368-1369; K. Prümm, "Mystères": Supplément au Dictionnaire de la Bible VI, cols. 1-225; BorNKAMM, "Musterion": Theologisches Wörterbuch zum Neuen Testament IV, p. 809-834.

15 F. Zorell, Novi Testamenti Lexicon Graecum, Parisiis 1911, 368. 
b) En particular, algunos capítulos de la fe cristiana o por su naturaleza más excelentes y más difíciles para el entendimiento o manifestados por alguna revelación particular y no propuestos luego a todos los fieles, así por ejemplo, la obra de la redención, el misterio que es la persona de Cristo.

c) La plena visión del misterio, como sucede en el Apocalipsis.

d) Al misterio de Dios (a la obra de la redención : cf. arriba b) se opone en cierto modo en contenido y en nombre tó.m. tes anomías, esto es, cualesquiera consejos procedentes del diablo y de los hombres malos para detrimento y destrucción de la obra de Cristo ${ }^{16}$.

El mismo Prat ${ }^{17}$ había reducido los empleos y los sentidos de la palabra a los tres siguientes, sintetizando más todavía el argumento: I) Secreto de Dios relativo a la salvación de los hombres por Cristo, secreto hoy desvelado, Rom. 16,$25 ; 2)$ Sentido oculto, simbólico o típico de una institución: Eph. 5, 32 (sentido del matrimonio), de un relato, Dan. 2, I8, 27, 30 (sentido del sueño de Nabucodonosor), de una cosa o de un nombre: Apoc. I, 20 (sentido de las siete estrellas y de los siete candelabros); Apoc. 17, 5-7 (sentido del nombre de la gran Babilonia); 3) Acción oculta: 2 Thes. 2, 7 (el misterio de iniquidad), o que no es conocida, I Cor. 15 (el misterio de la resurrección futura).

Los tratadistas del sentido de "musterion" en la Escritura están conformes en esas nociones esenciales y más o menos insisten en ese aspecto de lo oculto y secreto del misterio. Algunos han pretendido trasladar ese significado a lo cultual, agregando que el pasaje era fácil para la Iglesia ${ }^{18}$. Una cosa parece cierta y es que "en la Santa Escritura no se encuentra la palabra musterion, aun cuando es traducida por sacramentum, aplicada al rito sagrado que constituye el sacramento... Las diez y seis veces en que musterion es traducido por sacramentum no comportan algun matiz especial, que modifique el sentido general de musterion" 19 . Se ha discutido mucho entre los autores al buscar un sentido cultual a la palabra, pero el mismo Prümm llega a la conclusión de que no hay lugar para ese sentido en la Escritura ${ }^{20}$.

En cuanto a la tradición cristiana griega, tras una lectura reposada

16 ID., o. c., 368-369, en la edición moderna, cols. 859-860.

17 F. Prat, La Théologie de saint Paul, Paris 1912, II, 394.

18 Cf. B. NeUNHeUSER, Baptême et confirmation, Paris 1966, que sigue en general en esto a 0 . Casel.

19 A. MiCHEL, a. c., col. 486.

20 Cf. K. Prǜm, a. c. 
de los textos patrísticos y de la bibliografía, se constata esto: conservan el sentido escriturístico y solamente misterios en plural comporta un cierto matiz cultual, como lo tenían los misterios o ritos mistéricos paganos, de cuyo influjo en los cristianos puede dudarse en general, aunque haya que admitirlo en casos concretos ${ }^{21}$. Sería largo recorrer los textos de los escritores eclesiásticos, desde los Padres Apostólicos a San Juan Crisóstomo o a San Cirilo de Jerusalén, ya que si van añadiendo algún elemento, permanece fundamentalmente el significado de algo oculto y que no se descubre a todos ${ }^{22}$. Bornkamm expone en la Iglesia antigua estas cuatro acepciones: $\mathbf{r}^{\circ}$ Realidades fundamentales de la salvación expresadas por musterion o musteria cristianos; $2 .^{\circ} \mathrm{Fi}$ guras y acontecimientos de carácter tipológico del Antiguo Testamento; $3 .^{\circ}$ Las verdades de la religión cristiana; $4 .^{\circ}$ Sacramentos ${ }^{23}$. Esta última acepción de misterio o misterios como sacramentos no viene atestiguada hasta pasado ya el siglo II. Sin embargo, en el mismo hecho de que a algunos de los por nosotros hoy llamados sacramentos se les denominara sacramento o misterio entonces, descubrimos solamente una asimilación a todas las demás realidades que se cobiian bajo el mismo nombre sin referencia especial al contenido actual. Habría un algo común en ellos: el sentido de cosa oculta y sagrada, no revelada a todos.

La evolución hacia un sentido más teológico, tal como "sacramentum" tendrá en una teología medieval y postridentina, no procede del griego, en que se mantiene su sentido profundo. Cuando se habla de la noción, sirve no sólo para los sacramentos como tales, sino vara toro otro misterio, al que se le aplicará también la definición de Orígenes: "Signum dicitur cum per hoc quod videtur aliud aliauid indicatur" ${ }^{24}$. Y habla a continuación de Jonás y de su signo de resurrección, y de la circuncisión de Abrahán como signo de la circuncisión espiritual de

21 Cf. O. CASEL, Le mystère du culte richesse du mystère du rhrist, Paris 1964; Th. FilthauT, La théologie des mystères. Exposé de la controverse, trad. franc., Desclée de Brouwer 1954; K. PRüMm, Der christliche Glaube und die altheidnische Welt. 2 vols., Leipzig 1935' ID., Christentum als Neuheitserlebnis. Fribourg-en-Br. 1939; U. RAHNER, Mysterion. Il mistero cristiano $e$ i misteri pagani. Trad. di D. Angelo Paredi, Brescia 1952; E. VoGT, "Mysteria" in textibus Qumran": Biblica 37 (1956) 247-257.

22 Los escritos principales de los Padres en lo referente a los sacramentos se hallan en la lista sumaria de J. DE GHELlinck, Patristique et Moyen Age, T. III. Compléments à l'étude de la Patristique, Bruxelles-Paris 1948, 173-177; J. Daniélou, L'entrée dans l'histoire du salut. Baptême et Confirmation, Paris 1967, en un apéndice, 144-156, titulado: Les sources de la théologie sacramentaire. 23 BORNKAMM, a. c., 831-834.

24 ORIGENes, In epist. ad Rom. IV, 2, PG. 14, 968, 
que habla San Pablo en Phil. 3, 3. Los sacramentos, pues, habría que entenderlos como todo otro misterio y su única eficacia en este sentido inicial patrístico provendría de la palabra -verbum-, como en cualquiera otro. Los griegos continuaban el sentido de la Escritura. San Agustín se conservará también en la misma línea, aunque amplíe las significaciones.

"SACRAMENTUM" y su uso.-Una anotación nos hará cautos y prudentes, antes de iniciar el recuento de conclusiones, sobre la evolución del término entre los latinos. Es Braun quien nos advierte, tras un resumen de explicaciones: "Como se ve, no se ha hecho claridad sobre las circunstancias en que sacramentum ha encontrado el musterion de la primitiva Iglesia y la penuria de documentos hace poco probable que puedan ser nunca perfectamente elucidadas" ${ }^{25}$.

El autor que centra ordinariamente el estudio sobre el uso de ese término es Tertuliano. Los autores están de acuerdo con Ch. Mohrmann, en decir que "no es invención suya, aunque él tenga una preferencia personal por esa palabra" ${ }^{26}$. Las conclusiones del artículo de la famosa filóloga son generalmente admitidas por los autores modernos, aunque algunos - lo veremos luego - lamenten que no haya hecho el examen detallado de los textos que, por otra parte, sabe que refrendan sus palabras. Mohrmann al fin de su estudio decía: "Mas he querido dimitarme a los textos más antiguos: es probable que mysterium haya sido empleado, desde el principio, para designar la doctrina cristiana, las verdades religiosas y sobre todo el sentido tipológico de las Escrituras. Sacramentum ha sido el sustituto universal de musterion, pero por razón del sentido inherente al motivo mismo de la palabra, sentido que no ha desaparecido nunca por completo, había $-\mathrm{y}$ ha - quedado más apto para dar el sentido litúrgico y sacramental que el sentido puramente teológico y abstracto, -razón por la que no ha podido suplantar nunca completamente a mysterium. Por otra parte, sólo lenta y penosamente mysteria, en plural, término técnico de los misterios paganos, tomará posesión del terreno sacramental" ${ }^{27}$.

El desarrollo que la ha conducido a esta conclusión podría resumirse

25 R. Braun, "Deus Christianorum". Recherches sur le vocabulaire doctrinal de Tertullien. (Publications de la Faculté des Lettres et Sciences humaines d'Alger, XLI), Paris 1962, 438.

26 Ch. MohrmanN, a. c., 235.

27 ID., $a . c ., 244$, 
de este modo, dado que sus estudios se han centrado sobre el latín de los cristianos. Tanto el griego como el latín han evolucionado bajo el influjo del cristianismo. Habría una primera evolución del griego al latín, pero habría también una evolución ulterior independiente del griego y que le ha avocado con facilidad al sentido que hoy tiene. No siendo además clara ni constante la doctrina, los términos fuctúan también y progresan por diversas vías. Esa latinización puede realizarse por la lengua corriente de las comunidades cristianas, a veces también por los traductores de la Biblia que dan a las palabras bíblicas términos latinos equivalentes, que son adoptados por la comunidad, con simbiosis de unas a otras expresiones ${ }^{28}$. En el proceso de latinización hay además algunas reglas que es preciso tener en cuenta. La primera sería ésta: "Las ideas abstractas son traducidas por palabras latinas, las cosas concretas -en el sentido más amplio de la palabra - son designadas por las mismas palabras griegas que las han introducido en Occidente". Como al principio mysterium era palabra abstracta, de aquí que se buscara un término latino capaz de traducirla, aunque no faltara en esta lengua un correspondiente real. Otra regla era la tendencia a la exclusión, que domina verdaderamente la evolución del latín de los cristianos en los primeros siglos, es decir, se trataba de excluir de su vocabulario aquello que sonara a algo en profano. Por eso los mysteria que podía significar algo en los misterios paganos, entrarían sólo más tarde y con mucha reticencia para designar los misterios cristianos.

Las dificultades comenzaban al preguntarse por qué sacramentum ha sido adoptado como equivalente de musterion. Aquí se apela a diferentes hechos, al sentido profano de la palabra, consciente de otra regla de la latinización cristiana antigua, que usa la lengua profana común y no la especializada.

Sacramentum comportaba un doble elemento, uno iurídico y otro religioso: El sentido de juramento y de devotio cree Mohrmann que no es primario. El uso del latín profano en lo referente a esta palabra está definido por el sentido profano de embargo (engagement) religioso. "Esta idea fundamental puede desarrollarse de diversas maneras:

r. Embargo (engagement) religioso $\rightarrow$ admisión, por la vía de este embargo en una comunidrid religiosa $\rightarrow$ iniciación.

28 ID., $a, c ., 235$. 
2. Embargo religioso $\rightarrow$ el acto del compromiso jurídico y sagrado a la vez $\rightarrow$ juramento de iniciación.

3. Embargo religioso $\rightarrow$ lazo sagrado y jurídico $\rightarrow$ lazo, unión sagrada" ${ }^{29}$. El esquema de la iniciación está implicado en las dos primeras significaciones confirmada luego por un juramento. Se trataría de la iniciación al servicio militar y designaría luego el servicio militar mismo como sacramento. Y pasará, sumándose a ello el elemento religioso, a la iniciación cristiana.

Lo esencial es el elemento sagrado combinado con un sentido religioso y ése no se refiere a los misterios, como sostiene Casel. Posiblemente el sentido jurídico no le ha permitido ser término técnico de la lengua de los misterios, y así se distingue de iusiurandum por el elemento sagrado, y de initiatio por el elemento jurídico. El elemento sagrado se ha reforzado por la morfología de las palabras en -mentum y así de sacer y de sacra en la debilitación del lenguaje se llegó a sacramentum. Hay otro hecho que es preciso revelar, porque tendrá su importancia y es el de lazo jurídico y sagrado.

¿De qué manera este sacramentum ha adoptado el o los sentidos de musterion? Son meras sugerencias o hipótesis, pero destituye de valor pleno y de probabilidad el que proceda de los traductores de la Biblia con su sentido primario de iniciación, aunque no falten puntos de contacto bíblicos. Existe una diferencia entre ambos por la diversa connotación de mysterium y de sacramentum: aquél tendría un matiz abstıacto y teológico, éste un elemento sacramental y litúrgico. Por eso piensa que no viene de las traducciones bíblicas, sino del uso común de las comunidades cristianas que al sentido bíblico de mvsterium asociaban ya un sentido más concreto y más bien sacramental ${ }^{30}$.

La evolución comenzaría en el siglo ir con los apologistas, partiría de los traductores de la Biblia y Tertuliano lo aplicaría en una gran multiplicidad de sentidos. Según Mohrmann, en Tertuliano no podría insistirse demasiaido en la relación con iuramento militar de sacramento cristiano, como se ha hecho en general (así De Ghellinck, Michel), ya que la base sería muy estrecha. No hay que olvidar que se trata de un artificio literario, muy común, comparando los elementos del tiempo y además que Tertuliano es un jurista ${ }^{31}$.

\footnotetext{
29 ID., a. c., 237.

30 ID., $a . c ., 241$.

81 ID., a. c., 242,
} 
Podríamos concluir su exposión con estas palabras que nos ponen en guardia: "En primer lugar: es preciso guardarse de precisar demasiado el uso más antiguo de sacramentum estableciendo, en las nociones, un cierto número de categorías rígidas y dando a cada palabra y a cada texto su lugar fijo en un esquema bien establecido. Es necesario darse cuenta del hecho que la lengua de Tertuliano y aun la de Cipriano estaba en pleno movimiento... como por lo demás las ideas y no podría aplicarse a su terminología flotante un sistema riguroso y escolástico. $\mathrm{Y}$ en segundo lugar: yo me pregunto si el uso de sacramentum ha sido verdaderamente tan universal como Tertuliano y las versiones africanas de la Biblia más antiguas sugieren" ${ }^{32}$.

Verheijen ${ }^{33}$, por su parte, ha buscado una pre-historia judía a la palabra sacramentum, sorprendido ante el hecho de que una palabra que significa "empeño", compromiso o lazo sagrado, traduzca una que significa secreto o cosa oculta, como es mysterium. Parte de un texto de Tertuliano en que aparece la identificación de sacramentum-signaculum, sacramentum fidei-signaculum fidei. "El sello bautismal evoca, para muchos autores del siglo Ir, alguna cosa que debe ser guardada o conservada intacta" "34. El lavacrum es obsignatio fidei y así nos dice: "Dicho de otro modo, el nuevo cristiano ha comenzado por renunciar al mal, primer aspecto de la fe que introduce y hace valer un segundo, el de adhesión a Dios, sin duda. Este doble compromiso de la fe se halla sellado en el baño bautismal. Es una sigilación de un estado ya existente: el corazón es puro desde la renuncia al mal" ${ }^{35}$. Lo prueba citando algunos textos de Tertuliano sobre el baño como sello y sigilación del compromiso o empeño adquirido por la fe profesada y la renuncia al mal. Así tendríamos el signaculum fidei como sello del sacramentum fidei.

Pero resulta que Verheiien encuentra el término sfragis, empleado por San Pablo a propósito de la circuncisión, si bien la identificación sfragis-bautismo no se halla en los libros bíblicos. Esa circuncisión iudía se opone en San Pablo a la circuncisión cristiana que es una circuncisión del corazón, y en contexto bautismal San Pablo usa también sfragisthein. Combinando los textos que cita, descubre que "para San Pablo el sello

\footnotetext{
ID., a. c., 242-243.

M. VERHEIJEN, a. $c$.

ID., 325 .

ID., 326-327.
} 
cs la circuncisión corporal, pero precisamente como nota exterior de la "circuncisión" espiritual; los judíos con los cuales tenía que batirse fundaban sobre la circuncisión corporal, como tal, su confianza; San Pablo les opone otro sello: la circuncisión del corazón, es decir, la fe, pero la fe que se presenta al baño de renovación en el Espíritu Santo. El sello-bautismo del siglo in parece ser un desarrollo de la terminología paulina. El punto de partida es el sello-circuncisión" ${ }^{36}$.

Nuestro autor continúa con otra constatación, a saber: que el sellocircuncisión no aparece sólo en San Pablo, sino también en textos rabínicos y el mismo Tertuliano conoce eso, cuando habla de in ipso signaculo corporis (Apol. 2I, 2). Su conclusión de la primera parte del artículo es ésta: "Sacramentum bautismal nos descubre a signaculum bautismal. De signaculum bautismal hemos llegado a sello-circuncisión. Es preciso distinguir el signaculum en sentido amplio, el bautismo, del signaculum en sentido estricto: la sigilación del compromiso cristiano por la inmersión ${ }^{37}$.

Prosiguiendo su encuesta ve que en la Biblia, en el Antiguo Testamento, las palabras traducidas por musterion es la hebrea sôd, y la traducen así Símaco y Teodoción y ellos son también del siglo Ir. Y sôd tiene estas significaciones: I) Sociedad, asamblea (para discutir o para deliberar); 2) La deliberación misma o su resultado: conversación, consejo, designio ; 3) Lo que se comunica a lo largo de la conversación: confidencia, secreto; 4) El espíritu que reina en la asamblea: intimidad. Sin embargo de las veintiuna veces que se emplea en la Biblia hebrea, algunas aparecen luego en comentarios rabínicos en relación con musterion y con circuncisión corporal. $\mathrm{Y}$ tras un breve análisis de textos rabínicos dice que "en el mundo judío rabínico, el término sôd ha indicado una cosa muy precisa: el sôd, el musterion, por excelencia, era la circuncisión que se hallaba indicada en el mismo ambiente por sello. Viviendo al lado de cristianos, había gentes para quienes stragissignaculum era equivalente de musterion" ${ }^{38}$. El paso de signaculum a sacramentum y sobre todo el sentido de lazo sagrado, de unión sagrada, le acercaba mucho más al sentido de sôd hebreo. Al fin puede concluir con estas palabras: "Si lo comprendemos bien, el sentido de sacramen- 
tum cristiano ha sido: I) Primeramente el de compromiso (engagement) cristiano, aproximándose a "sello que es preciso guandar intacto"; 2) Luego el de compromiso cristiano presentándose, al momento del sello, para ser sellado por el sello en sentido estricto, o la circuncisión del corazón que pide su sigilación; 3) Este mismo sacramentum ha devenido el equivalente-antítesis de sôd-circuncisión-sello-musterion y ha tomado así el sentido de misterio y de tipo; 4) La equivalencia sacramentumsôd ha valorizado y cristianizado su sentido antiguo de unión sagrada. Como en el caso de statio y de pax, la evolución de sacramentum en latín cristiano se explicaría así por los contactos de los cristianos con el mundo judío en el siglo II" ${ }^{39}$.

Como puede apreciarse son tesis complementarias y no contradictorias. En ambos casos está Tertuliano implicado, pues es él quien ofrece la posibilidad a tales exámenes. Usa el término. más de cien veces. Y por lo mismo queremos preguntarnos cuáles son los sentidos que Tertuliano da al término sacramentum. Además del interés particular que este hecho puede ofrecer para la teología sacramentaria en general, ofrece uno especial para el estudio de San Agustín, dado que el ambiente en que se desenvuelve el Obispo de Hipona está cargado de resonancias del jurista africano. Quizá más que en ningún otro habría que buscar los sentidos agustinianos de sacramentum en Tertuliano, del cual pasan a San Cipriano, tal vez a los mismos donatistas, y sin duda a Optato de Milevi.

E. de Backer agrupa ciento treinta y cuatro veces que emplea Tertuliano sacramentum en dos grandes clases: sacramento-juramento (ochenta y cuatro veces), con las ideas sucesivas de juramento militar $\mathrm{u}$ otro adjetivo, de rito de iniciación a los misterios, de religión en sentido objetivo, de verdad y de doctrina religiosa, de consagración (en sentido etimológico de la palabra sacramentum), de rito y sacrificio sacramental, de rito sacramental y de nota o garantía de la fe (= signaculum); y sacramento-misterio (cincuenta ejemplos), con las ideas sucesivas de símbolo, figura, alegoría, de misterio o cosa secreta y oculta, de disposición, plan, orden divino, de profecía ${ }^{40}$.

Braun en su estudio del vocabulario doctrinal de Tertuliano, tras

39 ID., 336-337.

40 E. DE BACKER, Sacramentum. Le mot et: l'idée représentée par lui dans l'oeuvre de Tertullien, Louvain 1911. Y en el vol. publicado bajo la diṛeción de De Ghellinck (v. nota 11) ocupa 59-152. 
hacer una relación de cuanto se ha dicho en torno al origen del uso de esta palabra en el autor africano y de sintetizar los diferentes puntos de vista en que están acordes los tratadistas, concluye así: "Reconozcámoslo, Tertuliano es perfectamente sincero y expresa por estas relaciones su convicción profunda de hombre para quien el servicio de Cristo requiere el empeño de todo el ser; pero es preciso renunciar a buscar en sus textos la menor indicación para reconstruir el camino semántico por el que sacramentum ha llegado a sus empleos cristianos" ${ }^{41}$. Hablaba del juramento militar y de la militia Christi ${ }^{42}$, que para muchos sería el sentido primario y el punto de partido y que él, con otros, como Mohrmann, Verheijen y Kolping, lo niega.

El uso del término sería ordinario en el latín corriente de los cristianos y para Tertuliano significa también "una verdad oculta a nuestra inteligencia y revelada por Dios" ${ }^{43}$. En su búsqueda y análisis del vocabulario docrinal de Tertuliano, tras un estudio de opiniones, concluye con los textos a la vista: "En singular el término designa:

a) De una manera general, el santo misterio del cristianismo, es decir, su santa doctrina. Sin determinación cuando el contexto lo permite, la palabra puede también ser precisada por nostrum, Christianum, Christi, religionis christianae o fidei; en algunos casos, el adjetivo totum permite insistir sobre la idea que este sacramentum, formado de las verdades doctrinales, constituye un conjunto solidario. Esta palabra servirá para designar la revelación divina contenida en los libros del Antiguo Testamento, thesaurus totius Iudaici sacramenti et inde iam nostri (Ap. 19, 2 (57)). Este sacramentum Iudaicum, llamado además sacramentum antiquitatis, nuestro autor sabe que no es absolutamente idéntico al sacramentum de los cristianos: en el $A d v$. Praxeam, donde trata de la doctrina trinitaria, dirá que Dios, por la revelación neotestamentaria, ha querido novare sacramentum (Prax. 3I, 2 (7)).

b) Tal misterio particular que forma parte de la doctrina revelada: así el dogma de la resurrección, el misterio trinitario (oikonomías sacramentum).

"En plural, el empleo es más raro en este sentido. La expresión nostra sacramenta (Ap. 47, I4 (6r, 62, 64)) designa las verdades de fe

41 R. Braun, o. c., 439-440.

42 Vid. también a A. KolPING, Sacramentum Tertullianeum. I (Untersuchungen über die Anfängen des christlichen Gebrauchs der Vokabel Sacramentum). Regiensburg-Münster 1948.

43 R. Braun, o, c., 440. 
concernientes a la escatología. Además, cuando opone el Dios creador, conocido de todos por el testimonio de sus obras, a la divinidad oculta de los Gnósticos y añade, certe et in sacramentis priorem et in praedicationibus manifestiorem, pensamos que es preciso relacionar la palabra a esta misma significación doctrinal : los "misterios" por los que el Dios de los judíos y de los cristianos tiene prioridad sobre el de los Gnósticos, son las verdades sagradas, y entre ellas la doctrina monoteista de que este Dios, desde el origen de los tiempos, ha comunicado el conocimiento a los hombres por los profetas" 44.

Se encuentra también en Tertuliano el matiz de lazo y de unión sagrada, de alianza sagrada. Y este sentido de asociación y de unión viene en contextos en que sacramentum se emplea por doctrina revelada, siendo "esta doctrina la que asegura la unión mística de los cristianos con su Dios". De esta suerte se le impone esta conclusión de su estudio : "Así sacramentum que llega a Tertuliano plenamente renovado por la influencia del musterion de la Sagrada Escritura, pero conservando sus matices propios (puesto el acento sobre la noción de sagrado, idea de lazo religioso) es una de las palabras que permiten mejor designar el contenido de la revelación, estando ésta formada por todas las verdades ocultas que Dios ha misteriosamente comunicado a los hombres para establecer con ellos su santa alianza y fundar sobre ellas la unidad de los fieles" ${ }^{45}$.

De la lectura de los textos de los demás autores, tanto de San Cipriano, como de San Hilario, de Optato de Milevi o de San Ambrosio, aparece claro que si, con intención parcialista, se quiere extraer la doctrina plena del signo eficaz de la gracia, se yerra, pues inmediatamente se admite que todos los demás sentidos no están al margen de ia significación y del empleo que se hace de la palabra. Tendremos luego ocasión de ver que San Agustín prosigue esta línea y la profundiza, aunque en la controversia donatista haya tenido que adentrarse por la explicación del sacramento del bautismo en especial.

Primeras conclusiones.-Nos pareció inútil hacer un estudio detallado de los nombres en los diferentes escritores eclesiásticos y citar los lugares en que ha sido empleada la palabra. Era para nosotros de mayor

\footnotetext{
44 ID., o. c., 440-441.

45 ID., o. c., 443.
} 
utilidad y más sustancioso recoger los últimos estudios sobre el particular, citándolos sin desvirtuarlos, para ir contorneando la significación de sacramentum y sentar bien los precedentes para entrar en San Agustín. Todos los estudios nos brindan aspectos instructivos que nos hacen cautos a la hora de examinar el contenido. Podríamos extraer en breve las siguientes conclusiones:

I. Esto nos permite encuadrar los sacramentos en los misterios en general del cristianismo, diríamos, en el misterio de nuestra redención, conservando de este modo su sentido original de algo oculto y secreto que sólo comprenderán los iniciados. Nuestros sacramentos tienen la significación de los misterios y la importancia que para la vida cristiana supone todo misterio con su invisibilidad y su manifestación.

2. El nombre no nos aleja del contexto bíblico, manteniendo su mismo sentido, aunque, como era natural, se ha ido enriqueciendo con matices nuevos, adquiriendo "sacramentum" un cierto matiz litúrgico y cultual, que inicialmente no existía en la Biblia y en sus traducciones. Neunheuser, a pesar de que, siguiendo a Casel, piensa siempre en lo litúrgico y cultual y en el influjo en ello de los misterios paganos, reconoce que "en todo caso, hay siempre para "sacramentum" esencialmente una referencia al griego musterion con toda la plenitud de sentido que este término implica, aun si una explicación clara y definitiva no es posible hasta que la palabra griega no sea totalmente explicitada" ${ }^{46}$. Tras haber intentado explicitar un poco más el sentido de "mysterium" y de "sacramentum" en el aspecto cultual y litúrgico, concluye con estas palabras: "Se exageraría ciertamente si se pensaba que estas designaciones de mysterium y sacramentum pueden bastar para brindarnos conocimientos decisivos; es preciso ciertamente'ser muy circunspectos cuando se sacan conclusiones de su significación. En particular, esta palabra, que la tradición cristiana ofrecía ya a los Padres, no significa en modo alguno que haya una dependencia causal entre los misterios paganos y los ritos cristianos" ${ }^{47}$. La conclusión que se impone a un lector atento y avisado es que, a pesar de los intentos que se multiplican por acercar la noción patrística a la medieval y tridentina, al menos la palabra no puede decirse que signifique lo mismo. El sentido de los Padres prosigue el camino bíblico, centrándose los sacramentos como todo otro misterio, en la historia de salvación.

46 B. NeUnheUser, o. c., 100.

47 ID., o. c., 101. 
3. Todo misterio que se expresa $-\mathrm{y}$ por tanto también los sacramentos - aporta algo, como realidad de la historia de salvación que se va realizando en el tiempo. Significan algo de esto, quieren expresarlo, darlo a entender, son símbolo, figura, tipo de algo invisible - planes de Dios - que se hace manifestación y luz en ellos. Los sacramentos van en esta línea y el que los Padres denominen "mysterium" o "sacramentum" al bautismo, a la eucaristía, o a la confirmación, indicaría solamente eso. Al ser misterio se comienza a entrar en relación personal con él por la fe -iniciación-, y esto une ya internamente a los fieles -lazo de unión, alianza-, pero como misterio manifestado tiene un algo visible y sensible -es el compromiso del signo, del gesto o de la palabra-empeño jurídico, sellado o signado por la imposición de las manos, o por el agua-, que a su vez une visiblemente a todos los sellados. Así la teología de los sacramentos se enriquece desde un punto de vista aun filológico.

$Y$ estamos en condiciones de poder añadir :

4. La palabra "sacramentum", sustituto latino universal de "mysterium" griego significa, por tanto, la doctrina cristiana, las verdades religiosas y sobre todo, el sentido tipológico de las Escrituras. Mas por su sentido etimológico era más apta para dar el sentido litúrgico y sacramental que el teológico. Por este mismo hecho no ha suplantado plenamente a "mysterium", quedando esta palabra más tarde para significar solamente el sentido teológico.

5. "Sacramentum" comportaba, como en el lenguaje pagano, un doble elemento, religioso y jurídico. Es un empeño religioso con tres ertadios: admisión por vía de compromiso en una comunidad -iniciación-; acto de compromiso jurídico y sagrado - juramento de compromiso - ; lazo sagrado y jurídico -lazo, unión jurídica-. Así sucedía también en la milicia y a ella se aplicaba este sentido primordial de la palabra, aún en el mundo pagano, insistiendo luego, los autores cristianos, sobre todo Tertuliano, en el parangón adaptándolo a la militia Christi. Ya se comprende que en este sentido la primera y básica apli. cación se haría al bautismo.

6. Lo esencial sería el elemento sagrado combinado con un sentido jurídico. Y se añade además el elemento de ser lazo sagrado y jurídico. Esto mismo nos explica el que también en el "sacramentum" que más tarde ha integrado la teología exista una especie de elemento jurídico y que lo esencial sea también el elemento sagrado. El elemento jurídico 
une a los demás miembros y obliga externamente a una profesión sincera y auténtica, en la vida, del empeño adquirido.

7. Por otra parte, las relaciones que el P. Verheijen ha visto completan esta visión del sacramento, aunque directamente se enderece al bautismo. Se conserva siempre, aún para el bautismo, el sentido de algo que hay que conservar intacto y oculto y así el sello bautismal. Entonces se comprenden los ritos bautismales, a los que recurre nuestro autor, siguiendo un poco a Tertuliano, pero que en realidad la tradición nos atestigua de ello de un modo o de otro: una renuncia al mal, un empeño adquirido por la fe, que sería encuentro personal con las exigencias, un baño que sella el empeño adquirido. Así el "signaculum fidei" sería el sello del "sacramentum fidei". La fe sería oculta y el baño sería el sello visible. He ahí el misterio y esto es lo interesante.

8. Se diría, pues, que lo externo -el baño- es el sello de lo interno, como la circuncisión corporal era el sello de la pertenencia a Dios y a su pueblo y a su vez la alianza con él. Ahora se trataría del sello-bautismo opuesto al sello-circuncisión: tendríamos una sigilación del empeño cristiano por la inmersión. A partir del hebreo sốd aparece el sentido de lazo sagrado, de unión sagrada, de alianza, pues sốd significa también asamblea, reunión, casi comunidad. El sentido de alianza sagrada se aplica a las demás verdades religiosas profesadas, por las que los adeptos se unen. Es decir, las verdades religiosas misteriosas admitidas crean también unidad.

9. Ahora bien, la aplicación de esto se hace ondinariamente en contexto bautismal, y la pregunta que surge es ésta: ¿Puede aplicarse también a los demás sacramentos, o mejor, es aplicado a los demás sacramentos y a cuál principalmente? Directamente se habla, además del bautismo, de la eucaristía, y el pan y el vino sellan el misterio de la unidad cristiana del pueblo de Dios con Cristo y con los cristianos entre sí. Todo esto estaría abriendo la vía ya a las consideraciones filosóficas que entrarían a formar parte de la explicación de los sacramentos, tales como se manifiestan en el período patrístico posterior. El paso no sería difícil y se recogieron los elementos que una filosofía podría tener apro vechables para una tal exposición. La escuela alejandrina, Teodoro de Mopsuestia y San Agustín completarán este cuadro.

ro. Se habrá notado a través de esta exposición un cierto personalismo y una ausencia. Etimológicamente se insiste en el empeño personal, sagrado y jurídico, en la profesión de fe, en el compromiso adqui- 
rido por medio de ella y luego en el sello que sigila lo que se ha realizado personalmente en actos precedentes. Todo ello depende, pues, de la persona que acepta el compromiso y que se empeña en cumplirlo, haciendo juramento de ello y sellándolo externamente. He ahí el personalismo. Y la ausencia nace de la misma insistencia en lo personal: ¿Ese empeño personal, esa fe que se profesa y con la que se compromete uno, quién la produce? El misterio aparece en lo invisible, dado que lo visible se manifiesta en los signos. Si lo externo es un sello de algo, ¿supone que lo sellado existe ya o puede decirse que comienza a existir desde el instante en que se sella, es decir, se pone el signo exterior? La ausencia, en otros términos, es la pregunta por la eficacia y la falta de respuesta. Se da por supuesto la existencia de lo invisible, pero no se nos dice de dónde procede: si del sujeto sólo, o lo produce en él la fuerza de la palabra que precede, o es obra conjunta y concomitante de ambos. El problema de la eficacia de los sacramentos no se ha planteado todavía y por tanto no se ha resuelto, ni quizá sea fácil verlo resuelto en el sentido que más tarde se comprendió en los escritores eclesiásticos.

\section{II. "Mysterium" y "sacramentum" en San Agustín.}

Con estos precedentes y con la tradición de la que Agustín sin duda no puede desprenderse y a la que recurrirá con mayor frecuencia en sus últimas polémicas, podemos entrar en el estudio de la sacramentaria agustiniana. Sus fórmulas han sido recogidas y elaboradas por los posteriores ${ }^{48}$ y quizá pudiéramos afirmar que no se han situado en su verdadero contexto ${ }^{49}$. Seguiremos de momento en estas páginas el mismo método que hemos usado para el estudio anterior, es decir, nos atendre.

48 A partir de San Isidoro de Sevilla que colecciona en diferentes fórmulas más o menos precisas el contenido. Dice así: "Sacrificium dictum, quasi sacrum factum, quia prece mystica consecratiur in memoriam pro nobis dominicae passionis; unde hoc eo jubente corpus Christi et sanguinem dicimus quod, dum sit ex fructibus terrae, sanctificatur, et fit sacramentum, operante visibiliter Spiritu Dei, cujus panis et calicis sacramentum Graeci eucharistiam dicunt, quod Latine bona gratia interprettatur. Et quid melius corpore et sanguine Christi?" (Etymol. VI, 19, 38, PL. 82, 255). "Sacramentum est in aliqua celebratione cum res gesta ita fit ut aliqua significare intelligatur, quod sancte accipiendum est. Sunt autem sacramenta baptismus et chrisma, corpus et sanguis" (Ibid., col. 255). Y así continua hasta el $n .42$ en breves definiciones y aclaraciones. Desde él ha pasado a la gran Escolástica.

49 Cf. J. MORÁN, "La noción agustiniana de "sacramentum" en la interpretación de J. L. Berti": Archivo Teológico Agustiniano. 2 (1967) 23-40. 
mos más bien al aspecto filológico, como base y auxiliar indispensable de nuevas investigaciones. El tema es ide una gran actualidad para los estudios agustinianos, como nos lo asegura la bibliografía ${ }^{50}$ y se planteó con precisión en el Congreso Agustiniano Internacional de París en r954. Las condiciones que en una de las discusiones exigía Audet para acercarse a la saoramentaria agustiniana me parecen justas y deseables. $\mathrm{Su}$ larga cita nos introducirá de la mano en el tema: "Para desprender la teoría sacramentaria de Agustín, es preciso abandonar nuestras categorías de signo según la acepción restringida que ha tomado, y sobre todo la noción de causalidad. Sería necesario partir de los términos latinos de San Agustín, me atrevería a decir, sin traducirlos.

"Es una verdad común que no hay tratado de sacramentis in genere en San Agustín, y la polivalencia del término en su obra hace todavía más difícil su interpretación. Los textos sacramentarios son innumerables: he adoptado tomar como base de mi estudio solamente aquellos en que se trata manifiestamente de hechos rituales. ¿En qué orden alistar esos textos y sus problemas? El orden cronológico es demasiado material en una producción tan dispar; el orden de los géneros literarios demasiado intrínseco a las obras, no satisface tampoco. Los grandes períodos doctrinales del gran Doctor con sus contextos y sus problemáticas bien definidas, me han parecido ofrecer un punto de partida objetivo muy agustiniano para su teoría sacramentaria. Si comenzamos por la problemática antimaniquea tomada al principio de su carrera pastoral, la cuestión sacramentaria se sitúa en un cierto contexto de exégesis y una problemática que le es impuesta por sus adversarios. Así la doctrina saoramentaria antimaniquea de Agustín es ante todo una justificación y una valorización de los hechos rituales del Antiguo Testamento. Agustín parte primeramente de una exégesis alegorizante para justificar los cuatro sacramentos del Antiguo Testamento: progresivamente literaliza su exégesis y llega a reconocer en estos hechos rituales sacramentos tan reales como los del Nuevo Testamento, pero al interior de la causalidad del signo. La noción virtus no está en modo alguno embargada en esta polémica. Además, Agustín ha sido condicionado muy de cerca, me parece, por el incidente de Antioquía sobre el que se ha encontrado con

50 En la nota 4 del art. citado en la precedente hemos recogido la principal bibliografía y a ella remitimos para no alargarnos, agregando: J. Garcfa CENTENo, "La dimensión sacramental de la Iglesia según San Agustín": Estudio Agustiniano 3 (1968) 491-503. 
Jerónimo. Es una circunstancia bíblica que le encamina a dar a los textos un valor más positivo. En cuanto a la interpretación especulativa toma a una filosofía del lenguaje signum, res, al fin de esta etapa de su exégesis. La res es Cristo, el signum son los sacramentos tanto del Antiguo como del Nuevo Testamento. No hay más que una cosa permanente, Cristo, presente en los signos, conjugados al pasado en el Antiguo Testamento, al presente y al futuro en el Nuevo.

"Pasando a la polémica anti-donatista, tenemos una problemática netamente eclesiológica, condicionada por el bautismo bajo el aspecto de su reiteración. Aquí todavía limita singularmente el problema. Habría que examinar en este ambiente todos los textos en que se trata de virtus sacramenti, término quizá tan ambivalente como sacramentum. Expresa, me parece, a la vez el valor que damos o recibimos de los sacramentos, y un valor más objetivo que proviene del sacramento mismo. Habría que examinar aquí la utilización de categorías paulinas, frecuente en este período de Agustín, la oposición forma-virtus en que forma es manifiestamente el rito mismo. Virtus es más difícil de definir. Hay en fin un aspecto de sacramentum que logra, no me atrevo a decir una categoría de causalidad, sino un aspecto de sacramentum muy próxima de nuestra noción de carácter, elemento que se ve raramente señalado y que ha sido bien puesto en luz por el P. Haring de Toronto, en su artículo: "St. Augustin's Use of the word Character", en la revista Mediaeval Studies, 1952, p. 79-97. Quedaría el período anti-pelagiano en que estamos al interior de un moralismo marcado, con la tendencia a dar más valor objetivo al hecho sacramental, con el fin de extraer argumento contra Pelagio" "51.

El tema estaría bien planteado de este modo en Agustín, y sería cuestión de examinar cada uno de esos períodos para hacernos con un cuadro relativamente completo de la sacramentaria agustiniana. Hay que admitir sin duda alguna en Agustín unos hechos iniciales, que sirven un poco para situar sus diferentes problemas teológicos. El ha resuelto los problemas según se le iban presentando y no es de maravillar que en cada una de las polémicas se atuviese a los datos que se le ofrecían y resolviera en conformidad con la oposición. Sin embargo, no puede aceptarse, sin restricciones y condicionales, que en sus contestaciones Agustín no tuviera presente la otra parte que pudiera interpelarle,

51 Th. AuDET, Discusión a la relación presentada por Gérad PHILIPs, "Le mystère du Christ": Augustinus Magister. III, Paris' 1915, 266. 
sobre todo en las últimas controversias, dado que, respondiendo a una, deja otra al descubierto, como más tarde se le achacaría en la polémica pelagiana en lo tocante a pecado y al mal. Aquí se ha fallado con frecuencia. Es decir, que puede exagerar y que en alguna ocasión ha sucedido eso a sus escritos. Mas no es admisible que olvidara las líneas generales de su pensamiento y el riesgo que corría en el equilibrio que buscaba.

Hay que convenir, empero, en que las líneas generales y directivas de su pensamiento son únicas a través de los diversos períodos, aunque siempre tengamos que reparar en el acento, dadas las circunstancias particulares de los varios escritos. Si ha ido planteando y resolviendo nuevas cuestiones a medida que se le presentaban, no olvidaba en su solución las precedentes, al menos en lo esencial. Lo contrario sería forjarse un Agustín sin talante llevado sin rumbo y sin ideas rectoras de su andamiaje religioso e intelectual.

Planteamiento.-Si convenimos en que Agustín en sus construcciones doctrinales no caminaba a la deriva, podemos preguntarnos: ¿Cuál es esa idea de fondo que a través de todas las polémicas permanece? O mejor, ¿cuáles son los pensamientos en torno a los sacramentos que ie ayudan a dar solución a las cuestiones planteadas por los diversos opositores? Algo se ha insinuado ya en lo precedente y la respuesta a estos interrogantes nos dará la clave de solución, internándonos en el tema que nos preocupa al presente.

Coincidiendo en la admisión de la existencia de ese pensamiento conductor de su doctrina, adelantamos que no podemos buscarlo en el empleo unívoco del término sacramentum o mysterium. No es cuestión de palabras, sino de pensamiento. En el período maniqueo, llevado de una exégesis alegorizante se atiene a los hechos rituales, y poco a poco pasa a una exégesis más literal, interpretando especulativamente a través de la filosofía del signum y de la res. En ella aparece como misterio auténtico Cristo. En lo sucesivo, a pesar de toda la alegoría o la tipología en la interpretación, se continúa y no se desprende de ella, nacido al contacto de San Ambrosio en relación directa con los alejandrinos y de una filosofía muy suya. Fundamentalmente tanto en la polémica donatista como en la pelagiana trabajan esos elementos también, aunque el acento se traslade, como se ha visto.

Pourrat, intentando una síntesis de la sacramentaria agustianiana, decía que "en los escritos agustinianos hay dos concepciones de sacra- 
mento: la una, muy general, es aplicada indistintamente a toda clase de ritos, es la del sacramento simple signo; la otra, más precisa, está reservada a algunos ritos solamente, en particular a la eucaristía y al bautismo, es la del sacramento signo al que está ligado un don o un efecto objetivo" ${ }^{52}$. Nos preguntaríamos si son dos concepciones o es más bien una, que se perfecciona, pero cuya esencia permanece siempre. El caso especial de esos dos sacramentos, eucaristía y bautismo, nos ayudará a precisar con mayor detalle el sentido de sacramento, pero no evitará el que, dando a ésos también el nombre de sacramento, éstos participen del sentido general de aquél.

"SaCramentum"-"Mysterium" en la lengua de San Agustín.Con las conclusiones a que se ha llegado en el estudio de los escritores eclesiásticos anteriores al Santo, podemos hacernos ya una idea y confrontar cuanto Agustín pueda decirnos ahora sobre sacramento. El empleo de estas palabras en su obra será riquísimo y ayudará a comprender mejor el problema de fondo. De Ghellinck escribe a propósito del uso de la palabra "sacramentum": "Bajo la pluma de Agustín, el cual ha precisado con tanta firmeza y precisión las grandes líneas de nuestra teología sacramentaria, la palabra (sacramentum) reviste una diversidad increíble de sentidos, fuera idel de rito, en los que parece complacerse el pensamiento tan matizado del gran Obispo: El sentido exacto que es preciso dar a cada uno de los ejemplos que contienen los diez gruesos volúmenes de sus obras no es fácil de determinar: como prueba las confesiones del teólogo Vázquez, que no carecía de penetración al fin de una encuesta lexicográfica sobre el empleo de la palabra en una locución especial" ${ }^{68}$.

De modo casi exhaustivo entró en el estudio filológico del término Couturier, aunque haya textos que examinar nuevamente. Sus resultados como de obra paciente pueden ser admitidos en línea de máxima, aunque su propia advertencia luego de citar a Pourrat haya que tenerla muy en cuenta: "Se plantea la cuestión al espíritu de las relaciones entre estas dos concepciones: ¿están ligadas íntimamente o, en el fondo, son dispares y provienen de fuentes diferentes de inspiración? ¿Cuál tiene más lugar en su obra? $\mathrm{Si}$, en efecto, es la primera la más general -y parece ser así cuantas veces acompaña al término sacramentum una

52 P. Pourrat, La théologie sacramentaire, Paris 1908, 21.

53 J. DE GHellinck, Pour l'histoire du mot' "sacramentum", 16. 
explicación, o que parece dar una definición- si pues es la concepción más general la que domina, ¿qué valor atribuir a los textos aparentemente más netos en favor de la concepción más estricta? ¿No deformamos inconscientemente los textos agustinianos por estar penetrados de las ideas modernas sobre los sacramentos? ¿No les hacemos decir más de lo que contienen en realidad? De aquí un malestar inevitable al leer las citas agustinianas que esmaltan todos los tratados sobre los sacramentos: ¿No serían aislados? ¿No sería su sentido forzado?" ${ }^{54}$. Esta misma impresión hemos tenido muchas veces. El planteamiento de Couturier no puede ser más realista. En su amplio estudio analiza los tres empleos principales que él descubre del término sacramentum, a saber: sacramentum-rito, sacramentum-símbolo, sacramentum-misterio. El mismo nos asegura desde el principio que se ha visto en la imposibilidad de suparar el empleo de sacramentum y de mysterium. Esto nos indica ya algo y si quisiéramos hacer el parangón con cuanto hemos escrito antes tendríamos en ello un punto de enganche con la tradición corriente. "Una lectura paciente y lo más atenta posible, nos ha permitido descubrir dos mil doscientos setenta y nueve empleos de uno o del otro término" Con estos presupuestos entra en el análisis del tema y nos interesará principalmente en sus conclusiones, dado que para la interpretación de textos precisos es necesario recurrir al contexto y al lugar más concreto de este artículo.

El sacramentum-rito lo examina bajo puntos de vista rituales. Le interesa más lo dedicado al sacramentum-símbolo, internándose por el Viejo Testamento, buscando símbolos y descubriendo los que Agustín propone, pasando luego al Nuevo. A este segundo tema le dedica la mayor parte del trabajo (pp. 189-225). Y concluye con el sacramentummisterio.

La primera nota que hace Couturier en sus conclusiones es que el empleo de los términos es muy complejo y que a lo largo de su estudio se ha podido ver con claridad este hecho. Aunque será larga su conclusión nos brinda lo mejor de los estudios para nuestro argumento. Esperando que el lector nos lo agradezca copiamos lo siguiente: "Además, en el curso de nuestras búsquedas, hemos llegado a constatar y a deplorar su estrechez. No hay duda alguna que mysterium y sacramentum admi-

54 C. Couturier, "Sacramentum et Mysterium dans l'oeuvre de Saint Augustin": Etudes Augustiniennes, Paris 1953,-163-164.

55 ID., 164-165. 
ten equivalentes cuyo uso ejerce una influencia sobre su empleo, sea para atraerlos a su sentido propio, sea para rechazarlos hacia matices diferentes. Así, estupefacto de la lucha extraordinaria sostenida por Jacob contra el ángel, Agustín escribe: "¿Qué hay de comparable entre la potencia de un ángel y la de un hombre? Luego, hay misterio (mysterium); luego, hay sacramento (sacramentum); luego, hay profecía (prophetia); luego hay figura (figura)". ¿Admitiremos que a cada uno de estos términos corresponde una noción distinta? Mas el sacramentum se define por su carácter profético. Según el punto de vista en que se coloca, es una sombra del futuro, una figura del porvenir del que es preciso tratar de desbrozar su rostro según sus contornos, o al contrario un velo que cubre el misterio, hasta la hora marcada para la revelación del contenido místico. Alegórica su significación es distinta de su sentido literal; al secreto que contiene toma hasta su nombre. Finalmente entra en el inmenso dominio de los signos, sean ésos gestos o palabras, porque es la categoría que se relaciona a las realidades divinas. ¿Dónde trazar la frontera entre estos diversos términos? Las nociones que evocan se recubren totalmente o de manera parcial..."

El estudio de Couturier, profundo y extenso en textos agustinianos, ha dejado en claro algunas evidencias que recogemos:

I. La complejidad de la terminología agustiniana queda demostrada palpablemente y en cada caso se precisa un análisis detallado del texto y del contexto para desprender su significado real. El sacramentum implica algo sagrado y ha ido enriqueciéndose con el concepto de una cierta eficacia, pero no puede impunemente avocarse a ella sin un estudio precedente ${ }^{57}$.

2. Esto mismo nos está indicando que la noción ordinaria, moderna -en cuanto que viene repitiéndose a partir de la Edad Media, pasando por el Concilio de Trento - no se halla en San Agustín tal cual, aunque haya querido extraerse de diferentes testimonios agustinianos

56 ID., 264.

57 Ib., 265: "Sin duda alguna, estamos ya en posesión de un elementio de discernimiento: el sacramentum se mueve en el orden de lo sagrado; por ello, se distingue de todo signo, alegoría o secreto profanos. Pero la figura en sentido agustiniano, el anuncio profético, el velo, lo místico, ¿no se sitúan exclusivamente en el mismo plano que sacramentum? En cuanto podríamos juzgar, parece que la sola distinción real extrae su fuente de la eficacia atribuída como propia al sacramentum o mysterium: lo que explicaría muy bien cómo estos términos, y particularmente el primero, han tendido cada vez más a designar exclusivamente los símbolos eficaces por oposición a los otros que conservan los nombres de figura, velo y otros. Una vez más, sólo un estudio preciso podría mostrarlo, pero se ve su importancia". 
todos los elementos que componen nuestra definición. En consecuencia para el estudio de la sacramentaria agustiniana hay que situarse en su ambiente histórico y atenerse a su terminología y a su contenido.

3. El centro del sacramento en agustiniano es Cristo, que sería el misterio escondido de San Pablo, y que ha dividido la historia en dos vertientes bien diferenciadas ${ }^{58}$. Camelot ${ }^{59}$ ha desprendido y profundizado un poco la conclusión de Couturier sobre este punto. En ese centro será necesario recordar como lo ha hecho Couturier su unidad o diríamos más, su identidad con la Iglesia.

4. El sentido ritual tiene una importancia capital en el empleo de los términos y en el uso que ha hecho el Santo de ellos. Dos terceras partes del total quedarían reducidos a ese aspecto particular, to cual nos dará pie para nuevas investigaciones ${ }^{60}$.

5. La conclusión final es ya clara: si es verdad que Agustín ha perfeccionado y llevado su doctrina sobre el bautismo y la eucaristía a una altura no igualada, no lo es menos que la teoría general sobre los sacramentos es todavía imperfecta. "Se distinguen de los simples símbolos, en que implican una "celebratio"; de los ritos judíos, en que suponen el cumplimiento de las promesas del Antiguo Testamento; por tanto, fiestas y "sacramentales" no forman más que un grupo con ellos, mientras que los ritos de Israel participan de su eficacia" ${ }^{61}$.

Estas conclusiones del estudio filológico nos plantean diferentes cuestiones, que dejamos en compás de espera, para próximas internadas y ahora nos preguntaríamos solamente: ¿Con qué tradición contaba Agustín? ¿En qué consiste su originalidad en materia sacramentaria tan alabada por los autores? Si quisiéramos establecer una comparación

58 ID., 266: “Es posible discernir la orientación esencial? ¿De qué se trata a cada paso de nuestra investigación, sino de Cristo? El es la "vida de los sacramentos", pues de su costado abierto brotan, de su muerte y resurrección sacan su eficacia; y, puesto que la Iglesia le está inseparablemente unida, el "sacramento" mismo que hace presente a Cristo realiza al igual la unidad de su cuerpo que es la Iglesia... Por su advenimiento, divide en dos la historia del mundo, cumple las figuras, transforma los ritos; instaura una nueva economía, que es el reino de la gracia (sub gratia). Mas puesto que vivimos todavía sobre la tierra y caminamos en la fe, tenemos necesidad de la "leche de los sacramentos" (sacramentorum) que prepara nuestra inteligencia a la contemplación de la verdad eterna y nos hace participar a su vida".

59 P. Th. CAMELot, "Sacramentum". Notes de théologie sacramentaire augustinienne": Revue Thomiste 57 (1957) $429-449$.

60 C. Couturier, 1. c., 266: "No es menos necesario señalar la importancia considerable tomada en él por el sentido ritual: cerca de 1.200 ejemplos para los ritos cristianos; con 200 para los ritos judíos, se llega a un total de 1.400 , o sea, cerca de las dos terceras partes".

61 ID., 266-267. 
entre las conclusiones de la patrística en general sobre el empleo de "mysterium" y de "sacramentum" y las conclusiones del estudio filológico en san Agustín tendríamos que constatar una casi total identidad entre unas y otras, pero tendríamos que añadir que el Obispo de Hipona ha juntado en sus escritos sin grandes acentos cuanto los escritores precedentes han distribuído en sus obras. Se diría que es el punto de convergencia de la doctrina anterior, común y vivida por los fieles, y a su vez la profundización de la misma en nuevas categorías, suscitadas por las polémicas que ha tenido que mantener. En realidad, reduciríamos su originalidad al haber centrado con un acento muy especial el saoramento en Cristo, aplicándole para los signos la teoría de la "admonición" que ha ido extendiendo cada día más en su pensamiento ${ }^{62}$.

José MoRÁN

62 Hemos hecho una primera aproximación al tema en J. MoRÁN, "La teoría de la "admonición" en los diálogos de San Agustín": Augustinus (Homenaje al P. Victorino Capánaga, II), Madrid 1968, 257-271; "La teoría de la "admonición" en las Confesiones de San Agustín": Augustinianum 8 (1968) 147-154. 